\title{
National Policies for Higher Education Internationalization: A Global \\ Comparative Perspective
}

\author{
Daniela Crăciun
}

\section{What Do We Know About Higher Education Internationalization so Far?}

Higher education has always been international in scope (Guruz 2008; Matthews and Sidhu 2005). Nevertheless, against the backdrop of globalization and neoliberalism, nation-states - and, by extension, universities - have faced pressure to internationalize their practices at an increasing pace (Altbach et al. 2009; Brooks and Waters 2011). As such, higher education internationalization is talked about as a strategic priority for governments and is considered to be at the forefront of policy agendas around the world (Brooks and Waters 2011). Since the beginning, the main goals of the Bologna Process - specifically the harmonization and mobility aspects - have underscored an interest in internationalizing national higher education systems in Europe.

Despite this, there is little large-scale comparative research on the actual policies deployed by nation-states to internationalize their higher education systems. With some notable exceptions [see de Wit et al. (2015); Helms et al. (2015)], country level studies on internationalization policy typically focus on in-depth case studies or small-n comparative research. Nevertheless, internationalization does not occur in a vacuum. It only occurs at the intersection of cooperation and competition between nation-states, institutions, and individuals. Therefore, studies that have a narrow geographical scope-while providing valuable insights into the multidimensional fabric of the process - are limited in their ability to map the global reach and impact of internationalization. For instance, while it is commonly argued that internationalization and globalization phenomena have changed the face of higher

\footnotetext{
D. Crăciun $(\bowtie)$

Central European University, Budapest, Hungary

e-mail: craciun_daniela@phd.ceu.edu

(C) The Author(s) 2018
}

A. Curaj et al. (eds.), European Higher Education Area: The Impact of Past and Future Policies, https://doi.org/10.1007/978-3-319-77407-7_7 
education across the globe (Altbach 2016), it is less clear what this transformation entails on a country by country basis (Altbach et al. 2009).

This is not to say that internationalization has been a neglected phenomenon in higher education research. In fact, quite the opposite is true. In the last couple of decades, the topic has received so much attention from researchers that it would be "impossible to provide an overview claiming to be somewhere near complete" (Kehm 2003, p. 112). The fact that there is no universally accepted definition of internationalization (Altbach et al. 2009), is an important clue that it has taken different forms in different contexts. It is precisely because of this multi-faceted nature that "there is no simple, unique or all-encompassing definition", but it is also "not helpful for internationalization to become a 'catch-all' phrase for everything and anything international" (Knight and de Wit 1995, p. 16). This perpetual quest for generalization has led to a situation where internationalization is applied both when a university introduces an English-taught course and when the whole higher education system is overhauled to integrate an international dimension into its functioning and purpose.

The ubiquitous use of the concept (Teichler 2009) has resulted in what could be called a "Hegelian night in which all cows are black and eventually the milkman is taken for a cow" (Sartori 1970, p. 64). Namely, the process of conceptual traveling (applying the concept of internationalization to new contexts and cases worldwide) has led to concept stretching which has reduced the analytical purchase of internationalization' (Crăciun 2015). The lack of conceptual clarity has important implications not only for research, but also for public and institutional policy formulation and funding (Matei et al. 2015).

On the one extreme, one may ask whether internationalization is only a fad that has been boosted by semantic inflation aimed at giving birth to an 'internationalization industry' (Healey 2008) or 'business' (Jones and de Wit 2014). On the other extreme, the lack of clarity may lead to deficient policies that are not equipped to deliver the intended outcomes. For instance, in spite of the rhetoric support for internationalization from institutional and national leaders, many of the articulated objectives of internationalization have not been operationalized for implementation (Knight, 1994 cited in Childress 2009).

While these cases may seem to overstate the actual situation, they point towards the need for a broader and more systematic approach to make sense of the complexity and variety of national higher education policies. The present chapter takes this observation as its point of departure, and suggests a way forward by conducting a global census of national internationalization strategies and revealing the insights that such an extensive data collection exercise brings to light. As such, it argues that internationalization can better be understood if one looks at what governments actually do to forward internationalization. It attempts to answer questions like: Is strategic thinking about internationalization a widespread phenomenon? Is it an old or a new phenomenon? Which are the countries that pursue internationalization in a strategic fashion? What common characteristics do they have?

To answer these questions, the chapter proceeds as follows. Section "What Is Internationalization and What Role Does the Nation-State Play?" establishes a 
working definition of internationalization and delineates the importance of the nation-state in forwarding the process. Section "Data Gathering Protocols" discusses the data gathering protocol and the measures designed to ensure the reliability of the collected data and, as a result, of the findings that derive from it. Section "What Does a Global Map of National Higher Education Internationalization Strategies Reveal?" presents the insights that a global census of nation internationalization strategies reveals and their implications for internationalization research and practice. Finally, section "Conclusions and Further Research" summarizes the main arguments of the chapter and points towards some limitations and avenues for further research in this direction.

\section{What Is Internationalization and What Role Does the Nation-State Play?}

As we cannot dig for any construction without landscaping, it is important to establish how internationalization is understood in the wider literature and provide a working definition for the current study. The prevalent definition of internationalization (Childress 2009; de Wit 2010; Qiang 2003) sees it as "the process of integrating an international, intercultural, and global dimension into the purpose, functions (teaching, research and service) and the delivery of higher education" (Knight 2004). In other words, internationalization is taken to mean a shift from previously inward looking national higher education systems to outward looking ones. Moreover, internationalization is a multi-level phenomenon that spans across scales, including institutional, national, regional, international and transnational efforts (Altbach et al. 2009). Adopting such a broad definition has the advantage of catering for an eclectic mix of developments that have impacted on higher education systems and institutions. Nevertheless, this comes at the cost of watering down the concept and seeing any process that spills over or into the national borders as internationalization.

In this chapter, internationalization will be taken to mean the active engagement with the design of policies, plans, programs, strategies and approaches at various levels of decision-making so as to promote the idea of internationality in higher education. ${ }^{1}$ In other words, internationalization is seen as a process forwarded by active policy-making, not by drift. While this definition does not provide a more

\footnotetext{
${ }^{1}$ The chapter makes a clear distinction between two key concepts: 'internationality' and 'internationalization'. In order to differentiate these terms, the conceptualizations proposed by Brandenburg and Federkeil (2007) are employed. On the one hand, internationality refers to a state, and can be used to characterize an institution or a country's higher education system "current status or the status discernable at the date of data acquisition" (p. 7). On the other hand, internationalization refers to a process in which a university or a national system shifts - in a steered manner- "from an actual state of internationality at time $\mathrm{X}$ towards a modified actual status of extended internationality at time $\mathrm{X}+\mathrm{N}$ "(p. 7).
} 
exact account of what internationalization entails, it allows for the identification and investigation of specific and explicit policy endeavors to promote the process. In this context, understanding the role of different actors in the internationalization of higher education becomes crucial.

Traditionally, the University has been a medium for promoting national cultures through standardized teaching and research methodologies, which was dependent on the nation-state for funding (Scott 2000; van der Wende 2001). It is generally argued that globalization has challenged the very nature of higher education, pushing it to reform "both the content and scope of its activities" (Guruz 2008). Starting from the proposition that there is an inherent contradiction between "internationalization" which "reflects a world order dominated by nation-states", and globalization which involves a "process of global competitiveness", Scott contends that the very existence of the University has been challenged (2000, p. 4).

On the national level, internationalization is just "one of the ways a country responds to the impact of globalization, yet at the same time respects the individuality of the nation" (Knight, 1997 quoted in Kreber 2009, p. 2). However, these national response strategies impose two competing 'laws of motion' upon higher education: the internationalization of learning and the nationalization of its purposes (Kerr 1990). In other words, there is a tension between 'the internationality of substance versus the nationality of form' (Teichler 2002).

\section{Data Gathering Protocols}

The proposed analysis was carried out at the national policy level. This stance was taken for many reasons. To begin with, as a plethora of studies have shown, nation states still play a central role when it comes to steering higher education (Beerkens 2004; Enders 2004; Vlk 2006; Witte 2006). As such, higher education policy "still tends not only to reflect but to underscore the specific traditions and circumstances of individual countries" (Enders 2004, p. 361). Empirical research has shown that even countries with similar socio-economic and political conditions have distinct higher education internationalization policies (Callan 2000; Graf 2009; Luijten-Lub et al. 2005; Matei and Iwinska 2015).

Next, these plans express a political commitment to internationalization, and not just political rhetoric. In other words, they are an integral part of the policy output of any government that promotes a supportive culture towards internationalization. There are countries in which national policies are implicit rather than explicit, the USA being but one example of such a case. However, these cases are not dealt with in this chapter as internationalization by stealth is not the focus of the current investigation. Also, such plans push governments to operationalize their understanding of internationalization. Having a well-defined and coherent strategy has been shown to be an important ingredient for moving forward with internationalization efforts (British Council 2011; Henard et al. 2012). 
Lastly, the advantage of employing this strategy is that the unit of analysis remains constant on a cross-national basis. In turn, this allows for a consistent mapping and comparison of the cases. Moreover, it helps to establish the parameters of the study and represents a guide for data sourcing (Yin 2009).

In order to collect systematic information about national higher education systems and policies put in place to forward the internationalization process, the World Higher Education Database built by the International Association of Universities was used as a data sourcing guide. Because the website where the database is located was hard to use for such a comprehensive data collection exercise, a web scraping application in Python was built to gather the relevant information. This meant acquiring an offline library of documents with systematic, reliable, and valid information on national bodies responsible for international cooperation in higher

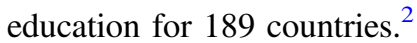

Two steps were taken to ensure the reliability of the collected data. First, at the moment of data collection, the existence (or non-existence) of a higher education international strategy was verified against scholarly literature and reports on the state of internationalization in the particular national context. Second, using groups of graduate students from various countries studying higher education policy, the results from a convenience sample of 11 observations ${ }^{3}$ were verified once again. For the test, intercoder reliability was adapted from manual content analysis to 'intercollector' reliability - the extent to which two or more independent data collectors agree on the coding of the content of interest (i.e. existence/non-existence of a higher education internationalization strategy). The measure of percent agreement was used a diagnostic tool for reliability and yielded a result of $100 \%$. All in all, the tests conducted attested to the reliability of the data collection process.

\section{What Does a Global Map of National Higher Education Internationalization Strategies Reveal?}

"Classifying is an activity inextricably linked to the human desire for creating order out of chaos" (van Vught et al. 2005, p. 9). Classifications - of which mapping is a sub-type - are spatial and/or temporal dissections of the world which "provide a systematic, nominal distribution among a number of classes or characteristics without any (intended) order of preference" (Ziegele 2013, p. 79). By assessing the similarities and differences between units and clustering them based on empirical information, they provide a description of the diversity within a system. As such, classifications are not aimed at assessing or establishing causality, but at promoting

\footnotetext{
${ }^{2}$ The final list of countries surveyed was 195, as the World Higher Education Database and the United Nations country lists were merged.

${ }^{3}$ The convenience sample included: Hungary, USA, Philippines, Albania, Romania, Saudi Arabia, Singapore, Greece, Croatia, Brazil, and South Korea.
} 
transparency. In other words, mapping is a purely descriptive endeavor that establishes indicators of diversity without assembling "a specific normatively fixed combination of features that stands for a type" (Ziegele 2013, p. 80). Mapping allows for the flexible combination of indicators and leads to the possibility of dynamic clustering. ${ }^{4}$

This extensive data collection exercise carried out for this research brought to light some interesting insights and patterns into higher education internationalization. Figure 1 presents a global map of national internationalization strategies around the world: the countries in dark grey represent those which do have a national strategy for internationalization, the countries in light grey represent those which have a section on internationalization in their general higher education strategy, and the countries in white those which do not have a higher education internationalization strategy.

Looking at the map, it becomes immediately apparent that thinking about higher education internationalization strategically is not a very widespread phenomenon: $80 \%$ of countries worldwide do not have any national higher education internationalization strategy. In fact, only $11 \%$ of countries - to be precise, 22 out of 195 countries-have an official strategy in this direction. Moreover, looking at the publication years of these documents shows that thinking strategically about higher education internationalization is a new phenomenon (see Fig. 2). Most of these strategies have been published in the last 5 years and, as a result, it is difficult to assess their results and impact.

These findings are surprising considering that national policies and the national context are considered to play the most important part in internationalizing higher education (Enders 2004; Graf 2009; Luijten-Lub et al. 2005). It is all the more surprising, if we consider that, since years, not only higher education institutions (Egron-Polak and Hudson 2014; European University Association 2013) but also supranational organizations (European Commission 2013; Henard et al. 2012) have encouraged and supported the participation of the nation-states in the process.

In alphabetical order, the countries that have a higher education internationalization strategy are: Australia, Belgium, Canada, Cuba, Denmark, Estonia, Finland, Germany, Ireland, Japan, Kazakhstan, South Korea, Lithuania, Malaysia, The Netherlands, New Zealand, Norway, Poland, Singapore, Spain, Switzerland, and the United Kingdom. Looking at the characteristics of these countries, various findings in relation to internationalization become apparent.

First, thinking about higher education internationalization strategically is mainly a European phenomenon. If we look at the distribution of the countries according to world regions (based on United Nations Country Grouping) we find the following distribution of countries which have a national higher education internationalization strategy: 13 in Europe, 5 in Asia, 2 in Oceania, 1 in North America, 1 in the

\footnotetext{
${ }^{4}$ Per se, classifications and maps are static because they portray a structure at a defined point in time (i.e. when data was collected). However, what is meant here is that users can dynamically combine indicators to produce different classifications.
} 


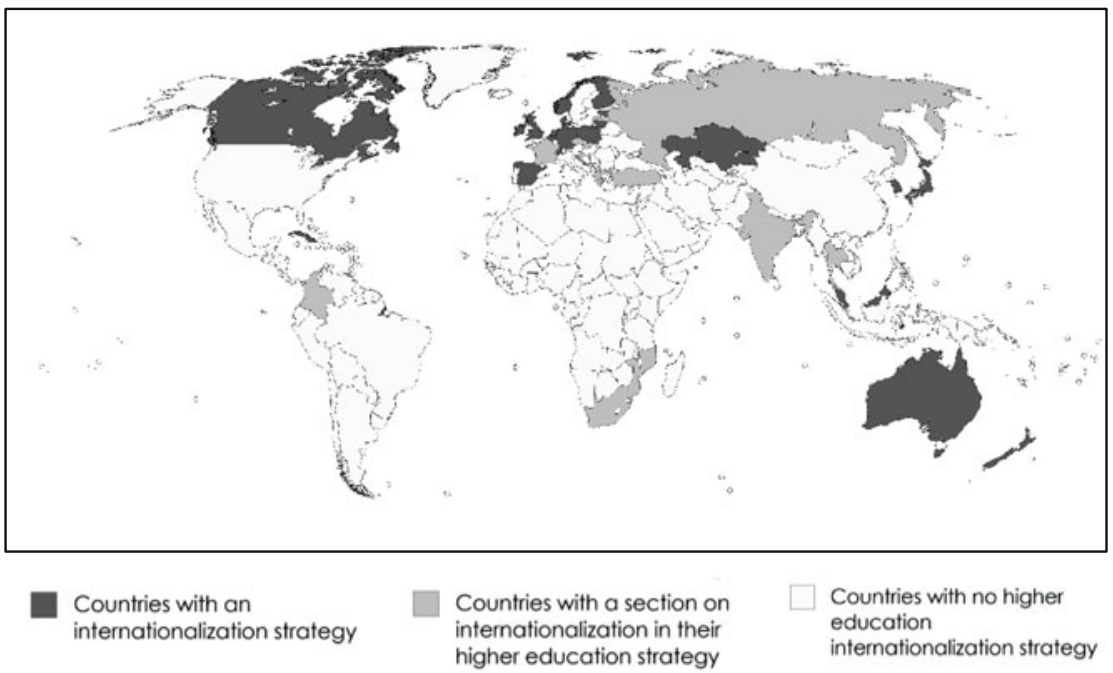

Fig. 1 A global map of national internationalization strategies. Source Compiled by author

\section{Publication years of strategies}

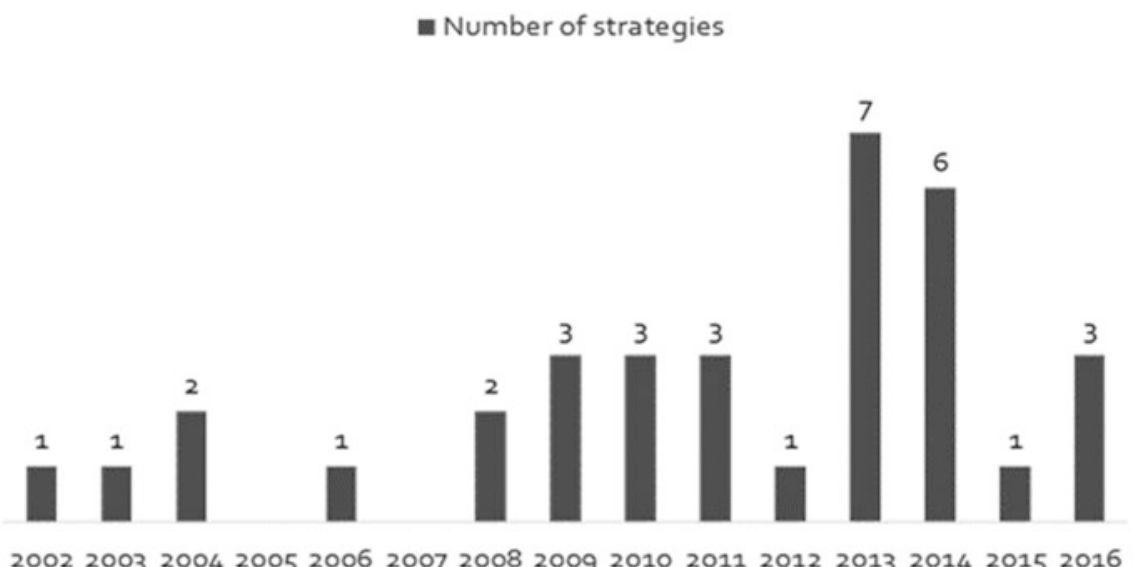

Fig. 2 Publication years of national internationalization strategies. Source Compiled by author

Caribbean, and zero in Africa, Central America, the Middle East, and respectively South America. Nevertheless, internationalization is not so much related to the Bologna Process and the European Higher Education Area (which have 49 member countries) as it seems to be to the European Union (11 out of the 13 countries are EU member states). An explanation for the lack of national internationalization 
strategies in so many of the Bologna countries could be that the Process already covers some of the central aspects of internationalization and also promotes a sort of regional internationalization in the area through its harmonization policies.

Second, thinking about higher education internationalization strategically is mainly a developed country phenomenon. If we look at the Organization for Economic Cooperation and Development (OECD) membership - which is an intergovernmental organization with 35 member countries founded in 1960 to stimulate economic progress and trade-we find that $77 \%$ of the countries which have a higher education internationalization strategy are OECD members $(n=17)$.

Third, the countries that have a higher education internationalization strategy receive the lion's share of internationally mobile students. Out of over 4.1 million higher education students who studied abroad in 2013 (Project Atlas 2016), the 35 OECD countries attracted $73 \%$ of them (OECD 2016). By comparison, nine of the countries with a national higher education internationalization strategy hosted $41 \%$ of all students who studied abroad in 2013: 12\% UK, 7\% in Australia, 6\% Canada, $6 \%$ Germany, 4\% Japan, 2\% The Netherlands, 2\% Spain, 1\% Finland, 1\% New Zealand (Project Atlas 2016).

It is already common knowledge that "the reality of international education is geographically uneven and far from global in scope and reach" (Brooks and Waters 2011, p. 45). Internationally mobile students are not evenly distributed across countries, but they are highly concentrated in economically advanced states, especially Anglo-Saxon societies (Guruz 2008). Research has shown that more than $50 \%$ of the students who study abroad are clustered in just four English-speaking countries: United States of America, United Kingdom, Australia and Canada (Hughes 2008). These countries have benefited from English being "the Latin of the 21 st century" (Altbach 2005, p. 66) and the reputation and capacity of their higher education systems (Hughes 2008). If data were openly available for all the countries, it is safe to say that the 22 countries with national internationalization policies probably receive more than half of the internationally mobile students worldwide. This is also because two-thirds of these countries have English - the academic Lingua Franca - as (one of) the official languages of instruction.

Certainly, the USA is the 'odd man out' in this respect as it does not have a national policy for internationalization. This can be explained by the fact that, unlike in most other countries, the responsibility for steering higher education in the USA does not fall on the national government, but on the state government. While there have been calls for a federal level policy, the main arguments against it have been the size, institutional diversity, and decentralization of the US higher education system (Helms 2015). The question then becomes, what is the state level engagement with higher education internationalization?

Traditionally, "states have been ambivalent, if not outright hostile, toward the international engagements of their colleges and universities" (Lane et al. 2014, p. 24). Recent research on the current state of affairs has concluded that support for internationalization at state level is quite limited as there are: very few states with an international higher education policy agenda (mostly Study in initiatives that are in fact run and financed mostly by higher education institutions through membership 
fees), little state funding (in 2016 only $5 \%$ of universities had received state funding for internationalization), and a lack of a formal administrative structures to manage internationalization (Helms 2015; Helms et al. 2017; Lane et al. 2014). In fact, it continues to be the case that "most international efforts continue to come from faculty members, students, and staff members" (Lane et al. 2014, p. 3), and that "internationalization-related support is still very much centred on individual opportunities and activities" (Helms 2015, p. 27).

A possible explanation for this state of affairs could be that other countries adopted comprehensive internationalization strategies as a catching up mechanism to compete with USA (this claim is supported by the fact that the adoption of national policies in other parts of the world is very recent). Further research on the matter would be needed to test this hypothesis. However, it can be reasonably concluded that while US higher education is at an advanced level of internationality, there is little system-level support for internationalization.

\section{Conclusions and Further Research}

The internationalization of higher education remains a messy field, as only timid attempts were made to systematize the process (Kehm 2003). The chapter showed how large-scale comparative research of national higher education internationalization strategies can bring to light new aspects of the process that would otherwise be obscured in small-n in-depth case studies. All in all, the chapter advocated for mapping higher education internationalization policies around the world to make the diversity of the system transparent. In itself, the mapping exercise is purely descriptive. However, it allowed one to observe variations in the data and pose tentative questions about the causality of patterns. More empirical work is needed to catalogue these strategies.

Some of the main conclusions drawn from this global map of national internationalization policies were discussed. First, thinking about higher education internationalization in a strategic manner at national level is a relatively new phenomenon that is not as widespread as the literature might suggest. Second, strategic thinking about internationalization is mainly concentrated in developed countries more generally, and European countries more specifically. Third, $41 \%$ of all the international students worldwide are received by just nine of the countries that have an internationalization strategy in place. Finally, two thirds of the countries with a national strategy for internationalization also have English as (one of) the language (s) of instruction.

While these findings bring a new perspective on higher education internationalization around the world, further research is needed to dig deeper into the different rationales, approaches, and substantive measures that the countries employ to forward the process. A content analysis exercise on these strategies could easily reveal the similarities and differences between them, and open avenues for cooperation or completion between countries. Such a comparative perspective could also help to 
characterize and contextualize the European Higher Education Area within a global reference framework and highlight the particular aspects of regional internationalization forwarded through the Bologna Process. The main contribution of such an endeavor would be to increase the transparency of higher education policies for students, universities, policy makers, and businesses, and to ease consortia formation between universities and mutual agreements between states.

\section{References}

Altbach, P. G. (2005). Globalization and the university: Myths and realities in an unequal world. The NEA 2005 Almanac of Higher Education, 63-74.

Altbach, P. G. (2016). Global perspectives on higher education. Baltimore: John Hopkins University Press.

Altbach, P. G., Reisberg, L., \& Rumbley, L. E. (2009). Trends in global higher education: Tracking an academic revolution. Paris.

Beerkens, E. (2004). Global opportunities and institutional embeddedness: Higher education Consortia in Europe and Southeast Asia. University of Twente.

Brandenburg, U., \& Federkeil, G. (2007). How to measure internationality and internationalization of higher education institutions! Indicators and key figures, 92.

British Council. (2011). Global gauge.

Brooks, R., \& Waters, J. (2011). Student mobilities, migration and the internationalization of higher education. Basingstoke: Palgrave Macmillan.

Callan, H. (2000). Higher education internationalization strategies: Of marginal significance or all-pervasive? The international vision in practice: A decade of evolution. Higher Education in Europe, 25(1), 15-23.

Childress, L. K. (2009). Internationalization plans for higher education institutions. Journal of Studies in International Education, 13, 289-309.

Crăciun, D. (2015). Internationalization in higher education. Perspectives of Innovations, Economics \& Business, 15(1), 49-57.

de Wit, H. (2010). Internationalization of Higher Education in Europe and its Assessment, Trends and Issues.

de Wit, H., Hunter, F., Howard, L., \& Egron-Polak, E. (2015). Intrnationalisation of higher education: Study.

Egron-Polak, E., \& Hudson, R. (2014). Internationalization of higher education: Growing expectations, fundamental values.

Enders, J. (2004). Higher education, internationalisation, and the Nation-State: Recent developments and challenges to governance theory. Higher Education, 47, 361-382.

European Commission. (2013). Communication from the commission to the European parliament, the council, the European economic and social committee and the committee of the regions: European higher education in the world. COM, 2013, 499.

European University Association. (2013). Internationalization in European higher education: European policies, institutional strategies and EUA support. Brussels.

Graf, L. (2009). Applying varieties of capitalism approach to higher education: Comparing the internationalization of German and British universities. European Journal of Education, 44(4), $569-585$.

Guruz, K. (2008). Higher education and international student mobility in the global knowledge economy. Albany: SUNY Press, State University of New York Press.

Healey, N. M. (2008). Is higher education in really "internationalizing"? Higher Education, 55, 333-355. 
Helms, R. (2015). Internationalizing U.S. higher education: Current policies, future directions. Washington. Retrieved from http://www.acenet.edu/news-room/Documents/Current-PoliciesFuture-Directions-Part-2-US.pdf.

Helms, R., Brajkovic, L., \& Struthers, B. (2017). Mapping internationalization on U.S. Campuses: 2017 Edition. Washington, D.C. Retrieved from http:/www.acenet.edu/news-room/ Documents/Mapping-Internationalization-2017.pdf.

Helms, R., Rumbley, L. E., Brajkovic, L., \& Mihut, G. (2015). Internationalizing higher education worldwide: National policies and programs.

Henard, F., Diamond, L., \& Roseveare, D. (2012). Approaches to internationalisation and their implications for strategic management and institutional practice: A guide for higher education institutions. Paris.

Hughes, R. (2008). Internationalisation of higher education and language policy: Questions of quality and equity. Higher Education Management and Policy, 20(1), 1-18.

Jones, G., \& de Wit, H. (2014). Globalized internationalization: Implications for policy and practice. IIE Networker, 28-29.

Kehm, B. M. (2003). Internationalization in higher education: From regional to global. In R. Begg (Ed.), The dialogue between higher education research and practice (pp. 109-119). Amsterdam: Kluwer Academic Publishers.

Kerr, C. (1990). The internationalisation of learning and the nationalisation of the purposes of higher education: Two "laws of motion" in conflict? European Journal of Education, 25(1), 5-22.

Knight, J. (2004). Internationalization remodeled: Definition, approaches, and rationales. Journal of Studies in International Education, 8(1), 5-31.

Knight, J., \& de Wit, H. (1995). Strategies for internationalisation of higher education: Historical and conceptual perspectives. In H. de Wit (Ed.), Stratefies for internationalisation of higher education (pp. 5-32). Amsterdam: EAIE.

Kreber, K. (2009). Different perspectives on internationalization in higher education. New Directions for Teaching and Learning, 118, 1-14.

Lane, J. E., Ownes, T. L., \& Ziegler, P. (2014). States go global: State government engagement in higher education internationalization. New York. Retrieved from http://www.rockinst.org/pdf/ education/2014-05-28-States_Go_Global.pdf.

Luijten-Lub, A., van der Wende, M., \& Huisman, J. (2005). On cooperation and competition: A comparative analysis of national policies for internationalisation of higher education in seven European countries. Journal of Studies in International Education, 9(2), 147-163.

Matei, L., \& Iwinska, J. (2015). National strategies and practices in internationalisation of higher education: Lessons from a cross-country comparison. In A. Curaj, L. Deca, E. Egron-Polak, \& J. Salmi (Eds.), Higher education reforms in Romania (pp. 205-226). London: Springer.

Matei, L., Iwinska, J., \& Crăciun, D. (2015). Patterns of funding internationalisation of higher education: A conceptual framework for the study of internationalisation. In: A. Curaj, L. Matei, R. Pricopie, J. Salmi, \& P. Scott (Eds.) The European higher education area: Between critical reflections and future policies (pp. 205-219). http://doi.org/10.1007/978-3-319-20877-0_14.

Matthews, J., \& Sidhu, R. (2005). Desperately seeking the global subject: International education, citizenship and cosmopolitanism. Globalisation, Societies and Education, 3(1), 49-66.

OECD. (2016). Education at a glance 2016: OECD indicators. Paris. Retrieved from http://www. keepeek.com/Digital-Asset-Management/oecd/education/education-at-a-glance-2016_eag-2016en\#page 3.

Project Atlas. (2016). Project atlas infographics. Retrieved from https://www.iie.org/Research-andInsights/Project-Atlas/Tools/Current-Infographics.

Qiang, Z. (2003). Internationalization of higher education: Towards a conceptual framework. Policy Futures in Education, 2(1), 248-270.

Sartori, G. (1970). Concept misformation in comparative politics. The American Political Science Review, 64(4), 1033-1053.

Scott, P. (2000). Globalisation and higher education: Challenges for the 21st century. Journal of Studies in International Education, 4(1), 3-10. 
Teichler, U. (2002). Internationalisierung der Hochschulen. Das Hochschulwesen, 50(1), 3-9.

Teichler, U. (2009). Internationalization of higher education: European experiences. Asia Pacific education review, 10(1), 93-106.

van der Wende, M. (2001). Internationalisation policies: About new trends and contrasting paradigms. Higher Education Policy. Higher Education Policy, 14(3), 249-259.

van Vught, F., Bartelse, J., Bohmert, D., Burquel, N., Divis, J., Huisman, J., et al. (2005). Institutional Profiles: Towards a typology of higher education institutions in Europe. Retrieved from http://doc.utwente.n1/53776/.

Vlk, A. (2006). Higher education and GATS: Regulatory consequences and stakeholder's responses. University of Twente. Retrieved from https://www.utwente.nl/bms/cheps/phdportal/ CHEPSAlumniandTheirTheses/2006vlkdissertation.pdf.

Witte, J. (2006). Change of degrees and degrees of change: Comparing adaptations of European higher education systems in the context of the bologna process. University of Twente. Retrieved from https://www.utwente.nl/bms/cheps/phdportal/CHEPSAlumniandTheirTheses/ 2006wittedissertation.pdf.

Yin, R. K. (2009). Case study research: Design and methods. In L. Bickman \& D. J. Rog (Eds.), Essential guide to qualitative methods in organizational research (Vol. V). Thousand Oaks: Sage Publications. http://doi.org/10.1097/FCH.0b013e31822dda9e.

Ziegele, F. (2013). Classification of higher education institutions: The European case. Pensamiento Educativo, 50(1), 76-95.

Open Access This chapter is licensed under the terms of the Creative Commons Attribution 4.0 International License (http://creativecommons.org/licenses/by/4.0/), which permits use, sharing, adaptation, distribution and reproduction in any medium or format, as long as you give appropriate credit to the original author(s) and the source, provide a link to the Creative Commons license and indicate if changes were made.

The images or other third party material in this chapter are included in the chapter's Creative Commons license, unless indicated otherwise in a credit line to the material. If material is not included in the chapter's Creative Commons license and your intended use is not permitted by statutory regulation or exceeds the permitted use, you will need to obtain permission directly from the copyright holder. 